\title{
Doppler flow velocity waveforms in the fetal ductus arteriosus during the first half of pregnancy: a reproducibility study
}

\author{
C. Brezinka, T. Stijnen* and J. W. Wladimiroff
}

Departments of Obstetrics and Gynecology, and *Biostatistics, Erasmus University, Rotterdam, The Netherlands

Key words: Fetal Ductus Arteriosus, Early Pregnancy, Reproducibility

\begin{abstract}
Reproducibility of flow velocity waveform measurement in the fetal ductus arteriosus was studied in 52 normal pregnancies between 11 and 25 weeks of gestation. The flow velocity parameters studied were the peak systolic velocity, mean velocity, end-diastolic velocity, flow velocity integral and acceleration time. In each woman two consecutive measurements were performed with a time delay of 15 min. An acceptable reproducibility was achieved for all flow velocity parameters, except for the acceleration time and end-diastolic velocity.
\end{abstract}

\section{INTRODUCTION}

Since the introduction of fetal ductal velocity waveform recording by Huhta and colleagues', several reports have appeared on ducial flow velocities relative to normal late pregnancy ${ }^{2}$, indomethacin administration ${ }^{1.3 .4}$, fetal behavioral states ${ }^{5}$ and fetal breathing movements ${ }^{6}$. Reproducibility studics of Doppler measurements in the fetal ductus arteriosus during late pregnancy have demonstrated satisfactory results for peak systolic and mean velocity, but a poor reproducibility for the acceleration time?

Recently, combined transvaginal and transabdominal Doppler ultrasound has provided flow velocity data from the fetal ductus arteriosus as early as 11 weeks of gestation8. Reproducibility studies during late first- and second-trimester pregnancies are needed to test the potential clinical significance of ductal flow velocity recordings during this early stage of gestation.

In the present study the question was addressed whether the reproducibility of ductal flow velocity waveforms during early pregnancy is comparable with that established in late pregnancy.

\section{MATERIALS AND METHODS}

A total of 52 women consented to participate in the study. Gestational age varied between 11 and 25 weeks (mean 17 weeks). Pregnancy duration was derived from the last menstrual period and from ultrasonic measurement of the fetal crown-rump length or biparietal diameter.

A combined curved linear array and pulsed wave Doppler system (Hitachi 450) with vaginal and abdominal probes was used. The carrier frequency of the vaginal probe was $6.5 \mathrm{MHz}$ and for the abdominal probe $3.5 \mathrm{MHz}$. The cut-off level of the high-pass filter was set at $100 \mathrm{~Hz}$. The vaginal and abdominal probes operate at power outputs of less than $100 \mathrm{~mW} / \mathrm{cm}^{2}$ spatial peak/temporal average in both imaging and Doppler modes by manufacturer's specifications. Up until 13 weeks of gestation the vaginal approach was used, whereas afterwards waveforms were obtained using the abdominal probe with the woman in the semi-recumbent position. First, a two-dimensional image of the conventional short-axis view of the heart was obtained displaying the right ventricular outflow tract, including the pulmonary artery and ductus arteriosus. The interrogation angle between the Doppler beam and the ductus was kept below $10^{\circ}$. All blood velocity waveforms were obtained during fetal apnea. In each woman Doppler recordings of the ductus arteriosus were performed twice (times $t 1$ and $t 2$ ). The time delay between the two measurements was approximately $15 \mathrm{~min}$. Hard copies of each recording were made on a Sony A4 printing device. These hard-copies were encoded so as not to reveal the identity or gestational age of the patient or the date and time of the recording. After all hard copies had been collected and encoded they were shuffled and analyzed. Four consecutive waveforms of similar appearance were analyzed for $t 1$ and $t 2$. Both Doppler recordings and waveform analysis were performed by the same investigator (C.B.). Waveform analysis was carried out by using a conventional microcomputer linked to a graphics tablet as described previously? ${ }^{7}$ The analyzing program used 400 data points to describe the four waveforms on one hard copy.

Correspondence: Professor J. W. Wladimiroff, Department of Obstetrics and Gynecology, Academic Hospital Rotterdam-Dijkzigt, Dr. Molewaterplein 40, 3015 GD Rotterdam, The Netherlands 
Table 1 Mean, intra- and interindividual standard deviation (SD) and intraindividual coefficient of variation (CV) for various parameters measured in one group of 23 women before and one group of 20 women after 18 weeks of gestation

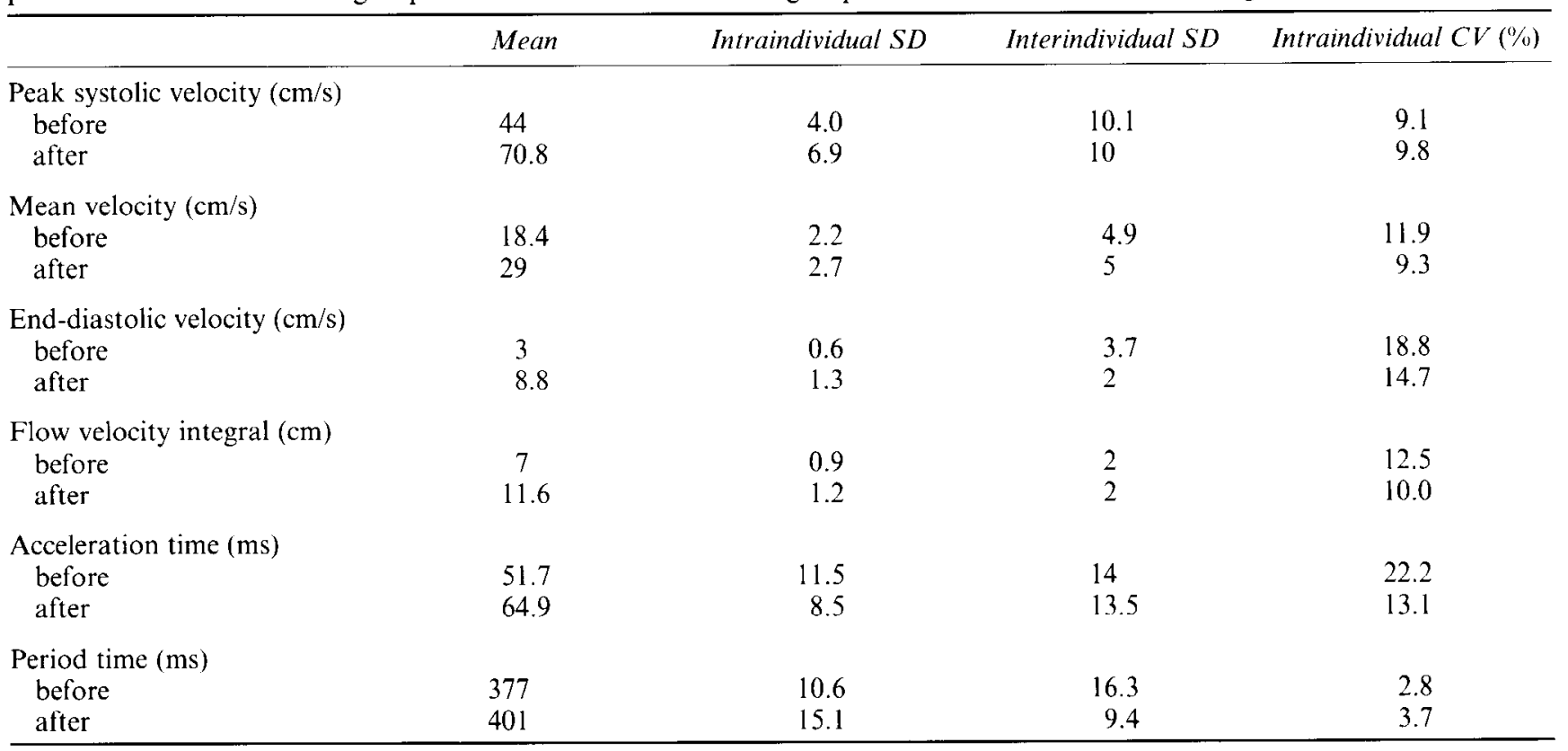

The following parameters were determined: peak systolic velocity, mean velocity, end-diastolic velocity, flow velocity integral, acceleration time and period time. Peak systolic velocities were measured from the zero line to the highest point of the Doppler velocity tracing. Mean velocity was calculated by dividing the sum of velocities over one period time by the number of data points. End-diastolic velocities were oblained by measuring from the zero line to the highest point at the end of the diastole. Flow velocity integral was determined by multiplying mean velocity by period time. Accelcration time was defined as the time interval between the onset of the waveform and peak systolic velocity.

\section{Statistical analysis}

For the periods 11-17 weeks and 18-25 weeks of gestation, the intraindividual and interindividual standard deviations were computed for each parameter using analysis of variance after checking the assumption of equal variances across patients. Reproducibility was expressed as the intraindividual coefficient of variation (i.e. intraindividual standard deviation divided by overall mean).

To investigate the possible relationship of reproducibility with time over the entire observation period, the relative difference of the $t 1$ and $t 2$ measurements were plotted against gestational age (i.e. $(t 1-t 2) /((t 1+t 2) / 2)$ against age). To test for a trend in reproducibility with gestational age, the absolute value of this relative difference was correlated with age using Spearman's correlation coefficient.

\section{RESULTS}

In nine women, seven of whom were below 16 weeks, no acceptable flow velocity recordings from the fetal ductus arteriosus could be obtained at $t 1$ or $t 2$. This was due to maternal ohesity and/or gross fetal movements, leaving 43 women for further analysis. Ductal end-diastolic velocity was absent until 13 weeks, appeared in some women at 14 weeks and was present in all women from 17 weeks of gestation. Results of the comparison between reproducibility of flow velocity parameters before 18 weeks $(n=23)$ and after 18 weeks $(n=20)$ are provided in Table 1. There was no significant change relatcd to gestational age in the percentage difference between $t 1$ and $t 2$ for all flow velocity parameters studied, except for the flow velocity integral $(r$ (Spearman $)=-0.31$, $p=0.04$ ).

\section{DISCUSSION}

The results show that reproducibility of flow velocity waveform recording expressed as the intraindividual coefficient of variation does not change with advancing gestational age during the period of 11-25 weeks of pregnancy. The change related to gestational age observed for the flow velocity integral appcars to be coincidental. Whereas peak systolic flow velocities display a significant rise with advancing gestational age ${ }^{8}$, variations between measurements within the same subject remained $<10 \%$ before and after 18 weeks. A similar pattern was observed for mean velocity and flow velocity integral. If end-diastolic velocities were present between 13 and 16 weeks, they were present during both $t 1$ and $t 2$. Similarly, when end-diastolic velocities were absent during $t 1$, they remained absent during $t 2$. Reproducibility of acceleration time was poor, as has been reported previously for late pregnancies? ${ }^{7}$. Although, in the present study, the sample volume was always taken in the distal part of the ductus, there may have becn minor variations in sample volume position between patients. Several reports have appeared on the effect of sample volume 
position regarding the acceleration time ${ }^{2.10}$. There were no significant differences in period time between the two consecutive recording periods. The large between-tests variation which was established for some parameters is therefore not affected by variations in heart rate.

All measurements were carricd out after the completion of embryonic structural development. The output levels for the transvaginal Doppler transducer are clearly situated in the lower region for output of Japanese and American ultrasonic diagnostic equipment ${ }^{\prime \prime}$.

It can be concluded that, in the ductus arteriosus, an acceptable reproducibility in the determination of peak systolic velocity, mean velocity and flow velocity integral can be achieved, indicating that these parameters can be used for assessment of cardiac function as early as the late first and second trimester of pregnancy. The reproducibility in determining acceleration time and end-diastolic velocity during this stage of pregnancy was poor.

\section{ACKNOWLEDGEMENT}

C. Brezinka is supported by grant JO-602/med of the Austrian Science Foundation.

\section{REFERENCES}

1. Huhta, J. C., Moise, K. J., Fisher, D. J., Sharif, D. S., Wasserstrum, N. and Martin, C. (1987). Detection and quantitation of constriction of the fetal ductus arteriosus by Doppler echocardiography. Circulation, 75, 406-12

2. Van der Mooren, K., Barendregt, L. G. and Wladimiroff, J. W. (1991). Flow velocity waveforms in the human fetal ductus arteriosus during the normal second half of pregnancy. Pediatr. Res., 30, 48790

3. Kirshon, B., Mari, G., Moise, K. J. Jr and Wasserstrum, N. (1990). Effect of indomethacin on the fetal ductus arteriosus during treatment of symptomatic polyhydramnios. J. Reprod. Med., 35, 529-32

4. Tulzer, G., Gudmundsson, S., Tews, G., Wood, D. C. and Huhta, J. C. (1992). Incidence of indomethacin-induced human fetal ductal constriction. J. Matern. Fetal Invest., 1, $267-9$

5. Van der Mooren, K., Van Eyck, J. and Wladimiroff, J. W. (1989). Human fetal ductal flow velocity waveforms relative to behavioral states in normal term pregnancy. Am. I. Obstet. Gynecol., 160, 371-4

6. Van Eyck, J., Van der Mooren, K. and Wladimiroff, J. W. (1990). Ductus arteriosus flow velocity modulation by fetal breathing movements as a measure of fetal lung development. Am. J. Obstet. Gynecol, 163, 558-66

7. Groenenberg, I. A. L., Hop, W. C. J. and Wladimiroff, J. W. (1991). Doppler flow velocity waveforms in the fetal cardiac outflow tract: reproducibility of waveform recording and analysis. Ultrasound Med. Biol., 17, 583-7

8. Brezinka, C., Huisman, T. W. A., Stijnen, T. and Wladimiroff, J. W. (1992). Normal Doppler flow velocity waveforms in the fetal ductus arteriosus in the first half of pregnancy. Ultrasound Obstet. Gynecol., 2, 397-401

9. Panidis, I. P., Ross, J. and Mintz, G. S. (1986). Effect of sampling site on assessment of pulmonary artery blood flow by Doppler echocardiography. Am. J. Cardiol., 58, 1145-7

10. Shaffer, E. M., Snider, A. R., Serwer, G. A., Peters, J. and Reynolds, P. A. (1990). Effect of sampling site on Doppler derived right ventricular systolic time-intervals. Am. J. Cardiol., 65, 950-2

11. Ide, M. (1989). Acoustic data of Japanese ultrasonic diagnostic equipment. Ultrasound Med. Biol., 15, 49-53 